\title{
Experimental Study of Aged and Seriously Damaged RC Beams Strengthened Using CFRP Composites
}

\author{
Ning Zhuang $\mathbb{D}^{1,2}$ Honghan Dong, ${ }^{1,2}$ Da Chen $\mathbb{D}^{1,2}$ and Yeming $\mathrm{Ma}^{1,2}$ \\ ${ }^{1}$ Jiangsu Key Laboratory of Coast Ocean Resources Development and Environment Security, Hohai University, Nanjing, China \\ ${ }^{2}$ College of Harbor Coastal and Offshore Engineering, Hohai University, Nanjing, China \\ Correspondence should be addressed to Da Chen; chenda@hhu.edu.cn
}

Received 11 April 2018; Revised 13 August 2018; Accepted 18 September 2018; Published 21 October 2018

Academic Editor: Alain Portavoce

Copyright (C) 2018 Ning Zhuang et al. This is an open access article distributed under the Creative Commons Attribution License, which permits unrestricted use, distribution, and reproduction in any medium, provided the original work is properly cited.

This paper presents results from experiments on aged and seriously damaged reinforced concrete (RC) beams strengthened with different arrangements of external carbon fiber-reinforced polymer (CFRP) laminates and end anchorages. Seven RC beams from an old bridge, measuring $250 \times 200 \times 2300 \mathrm{~mm}$, were tested. All specimens were loaded to yield load to evaluate initial mechanical properties. Then, these seriously damaged specimens were repaired using different CFRP-reinforcing schemes and reloaded to failure. The yield load growth due to CFRP reinforcement ranged from $5 \%$ to $36 \%$. Different parameters including CFRP dimension and position, bonding length, and end anchorage were investigated and facilitated conclusions on beam ductility, loadmidspan deflection response, and failure mode. This research contributes to knowledge about the CFRP repair of aged and seriously damaged beams to ensure better performance in overloaded conditions.

\section{Introduction}

Reinforced concrete (RC) is one of the most widely used building materials in civil engineering applications. Aging of the material and overloading caused by misuse or unusual events may damage RC structures. Thus, RC components must be maintained and sometimes strengthened to improve their service life. Given the complex nature of RC construction methods, which require the use of heavy equipment, conventional reinforcement techniques are not appropriate. Carbon fiber-reinforced polymer (CFRP) products, which have a number of advantages (such as corrosion resistance, favorable strength-to-weight ratio, durability in adverse environments, and ease of application), have been widely accepted as new effective technologies for restoring or improving the performance of RC structures [1-6].

Bonding a CFRP sheet transverse to the axis of the member, or perpendicular to potential shear cracks, will increase the strength of the member [7-9]. Experiments have also shown that beams strengthened with CFRP can increase ultimate strength by $83-125 \%$ [10]. However, premature debonding failure due to separation of laminates has been shown to be the main problem of this method due to excessive stress concentration at the end of laminates [11]. Such failure can be avoided using different anchorage systems [12, 13].

On the contrary, the performance of aged RC elements of existing structures is different from that of newly constructed specimens in the laboratory because aged samples have been deteriorated by reinforcement corrosion, layer cracks, and concrete cover spalling for many years [14]. Very limited work has been conducted on aged RC elements strengthened by CFRP composites. Pantelides and Fitzsimmons [15] investigated the seismic rehabilitation with CFRP of RC bridge bents. Zanardo [16] studied the mechanical properties of a 40-year-old, four-span RC slab bridge that was retrofitted using the CFRP laminate. An in-service 1950s vintage RC deck girder bridge repaired with externally bonded carbon fiber laminates for shear strengthening was inspected by Williams and Higgins [17].

In addition to above studies, some laboratory experiments have been conducted on newly cast specimens to investigate the mechanical properties of damaged beams [18, 19]. For example, some experimental tests have investigated members strengthened with CFRP under preloading or precracking 
$[20,21]$. However, these studies focused on the mechanical performance of RC members that were slightly damaged. Actually, structures may be overloaded and damaged seriously, but little information is found in the literature regarding aged and seriously damaged structural members. Therefore, the main objective of this study was to examine the effectiveness of different CFRP sheet arrangements and end anchorages for improving the performance of aged and seriously damaged RC beams.

\section{Experimental Programme}

2.1. Test Programme. In the test programme, beam specimens from an old bridge were first tested in four-point bending with an effective span of 2,300 $\mathrm{mm}$ and a shear span of $900 \mathrm{~mm}$ to evaluate their initial strength, as illustrated in Figure 1. Load was applied at a displacement rate of $1.5 \mathrm{~mm} / \mathrm{min}$. The beam specimens were instrumented with linear variable differential transformers to measure vertical displacement at the midspan of the beam. Beam specimens were unloaded immediately when the load reached the yield load. Then, these seriously damaged beams were removed from the testing frame and repaired using different CFRP-reinforcing schemes. After maintenance for seven days, these repaired beams were reloaded to failure.

2.2. Specimen Configuration. Beam specimens had cross sections of $200 \mathrm{~mm}$ width by $250 \mathrm{~mm}$ height and length of $2300 \mathrm{~mm}$ (Figure 2). The test specimens were divided into two groups. Group one included three beams that had two steel bars of $16 \mathrm{~mm}$ nominal diameter for tension reinforcement with a clear cover of $40 \mathrm{~mm}$. Group two consisted of four beams that had three steel bars of $12 \mathrm{~mm}$ nominal diameter for tension reinforcement with a clear cover of $35 \mathrm{~mm}$. Table 1 and Figures 3-4 show the different CFRP-reinforcing schemes of the beam specimens.

2.3. Material Properties. The concrete compressive strength achieved from the core test was $50 \mathrm{MPa}$. The steel reinforcement was extracted from beam specimens after the test. A mass loss analysis was performed on the reinforcing steel bars in accordance with the standard ASTM GI-90 [22] to obtain the degree of corrosion. The average steel mass loss was $6.8 \%$ and $8.5 \%$ for Group one and Group two. The flexural reinforcement in test specimens was 16 and $12 \mathrm{~mm}$ nominal diameter steel with a yield strength of $360 \mathrm{MPa}$. The mechanical properties of the carbon fibers used are shown in Table 2 .

2.4. CFRP Repairing. Special consideration was given to surface preparation before strengthening the specimens with the CFRP sheet. The weakened surficial layer of concrete was removed from the beam by sandblasting, and then cracks caused in the first loading were sealed by applying an epoxy gel adhesive. Finally, the surface was grounded and cleaned using a high-pressure air jet. The CFRP sheet was bonded to the tension face of the beams with the fibers oriented parallel to the longitudinal axis of the beams. When bonding the CFRP sheet, a primary layer of epoxy was applied to the bonding face first before the CFRP sheet was applied. Then, a secondary layer of epoxy was applied to the surface of the CFRP sheet and forced into the sheet using a paint roller. The properties of the epoxy gel adhesive used for sealing the cracks are shown in Table 3.

\section{Test Results and Discussion}

\subsection{Yield Load Growth}

3.1.1. Effect of CFRP Sheet Dimension and Position. The load capacity growth was greatly influenced by the dimension and the position of the strengthened CFRP sheet [23]. The percent increase of yield load could be evaluated as follows:

$$
\alpha_{\text {yield }}=\frac{f_{\text {str }}-f_{\text {bef }}}{f_{\text {bef }}} \times 100 \% \text {, }
$$

where $\alpha_{\text {yield }}=$ the percent increase of the yield load, $f_{\text {str }}=$ the yield load after strengthening $(\mathrm{MPa})$, and $f_{\text {bef }}=$ the yield load before strengthening ( $\mathrm{MPa})$.

The yield load grew by 5 to 36 percent as beams were strengthened with different CFRP schemes, as shown in Figure 5. In Group one, the yield load of specimens WA, LEU, and WE increased by 5\%, 32\%, and 36\%, respectively. Beam WE showed a higher yield load growth compared with beam LEU. The main reason was that beam LEU was locally strengthened in the middle flexure zone $(800 \mathrm{~mm})$, while beam WE was strengthened in full span. Seriously damaged beams tend to crack more easily with increasing loads especially as RC materials have already aged. Locally strengthening flexural span could not prevent or restrain the formation of shear cracks, which could lead to excessive distress. In Group two, the yield load of beams LEA-S, WEA-S, LE-S, and WPA-S increased by $22 \%, 26.6 \%, 8.6 \%$, and $12 \%$, respectively. The yield load growth of beam WEA-S was approximately $13.2 \%$ higher than that of beam WPA-S because beam WPA-S was also locally strengthened in the middle flexure zone. Thus, when flexural strengthening was applied to a seriously damaged beam, its shear strength often required enhancement.

For aged and seriously damaged beams, flexural/shear cracks would also easily propagate in the beam side faces. A beam strengthened in the side face by the CFRP sheet was expected to exhibit superior performance compared to beams not strengthened in the side face [24]. So, in testing Group two beams, CFRP sheets were bonded onto the beam side faces to prevent premature debonding failure causing by side flexural/shear cracks.

3.1.2. Effect of Bond Length. As the CFRP sheet was used in conjunction with epoxy-laminating resin, the system was representative of the "dry lay-up" application technique for composite strengthening. The tension in the CFRP sheet was transferred to the concrete mainly via shear stress in the adhesive within a short distance nearest to the load application point. As the cracking of the concrete near the loading 


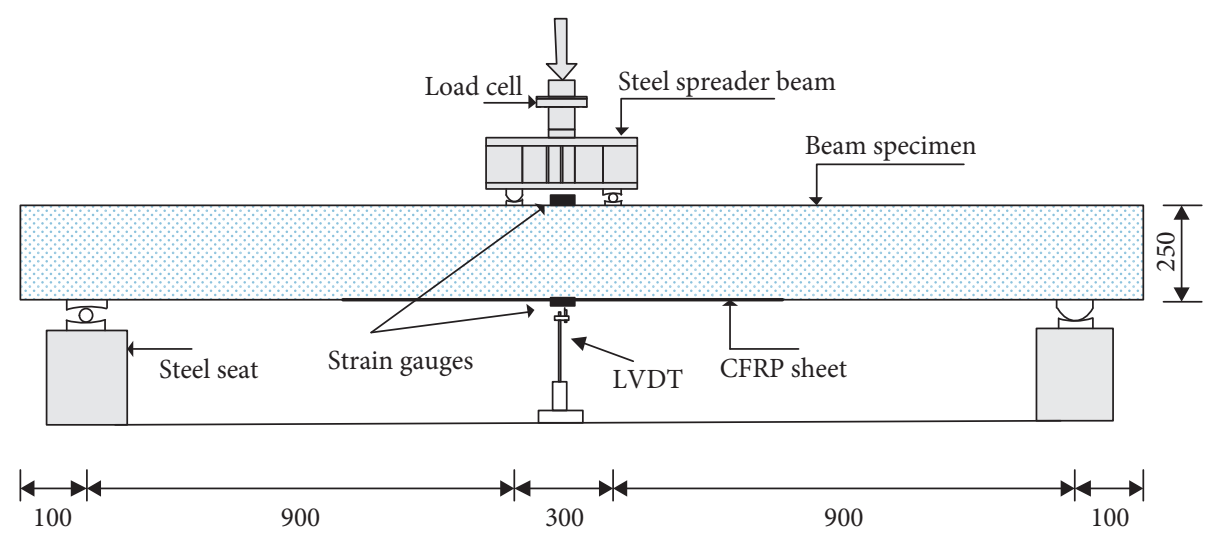

Figure 1: Schematic diagram of the test beam (dimensions in $\mathrm{mm}$ ).

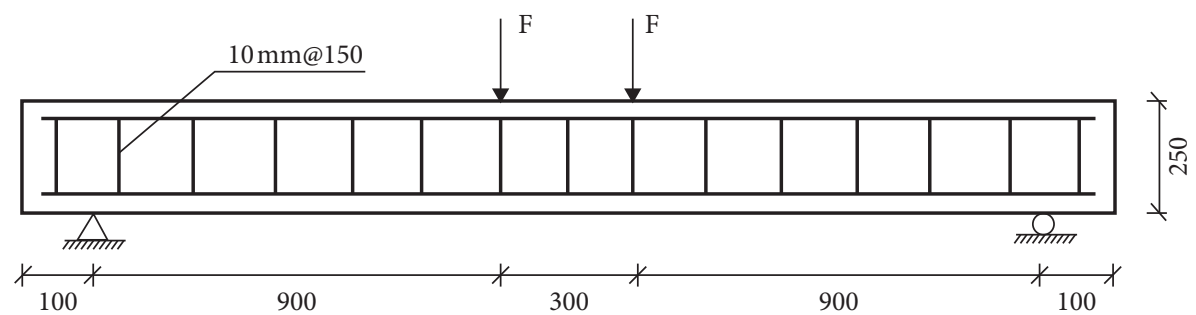

(a)

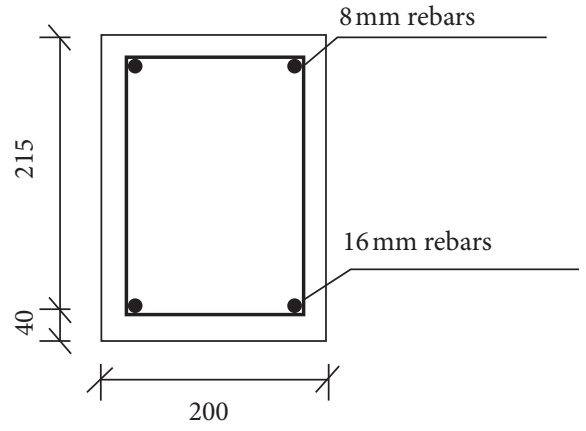

(b)

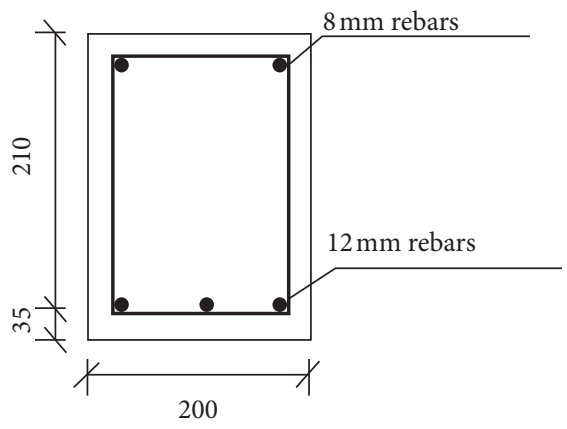

(c)

FIGURE 2: Configuration and reinforcement details of beams: (a) stirrup reinforcement; (b) beam cross sections of Group one specimens; (c) beam cross sections of Group two specimens (dimensions in $\mathrm{mm} ; F$ is the loading force).

TABLE 1: Test matrix.

\begin{tabular}{|c|c|c|c|c|c|}
\hline Group & Specimen & $\begin{array}{c}\text { Dimension and position } \\
\text { of the CFRP sheet }\end{array}$ & Anchoring schemes & $\begin{array}{c}\text { Greater than effective } \\
\text { bond length }\end{array}$ & $\begin{array}{l}\text { Beam side face } \\
\text { strengthening }\end{array}$ \\
\hline \multirow{3}{*}{ One } & WE & Full span & No anchorage & Yes & No \\
\hline & LEU & \multirow{2}{*}{$\begin{array}{l}800 \mathrm{~mm} \text { in the middle } \\
\text { Full span (only CF anchors bonded } \\
\text { with epoxy resin) }\end{array}$} & U-shaped wraps & Yes & No \\
\hline & WA & & CF anchors & No & No \\
\hline \multirow{4}{*}{ Two } & WEA-S & \multirow{4}{*}{$\begin{array}{c}\text { Full span } \\
800 \mathrm{~mm} \text { in the middle } \\
\text { Full span (only } 800 \mathrm{~mm} \text { bonded with } \\
\text { epoxy resin) } \\
800 \mathrm{~mm} \text { in the middle }\end{array}$} & CF anchors & Yes & Yes \\
\hline & LEA-S & & CF anchors & Yes & Yes \\
\hline & WPA-S & & CF anchors & Yes & Yes \\
\hline & LE-S & & No anchorage & Yes & Yes \\
\hline
\end{tabular}

L: local span strengthened with the CFRP sheet; W: whole span strengthened with the CFRP sheet; A: CFRP sheet fixed by CF anchors; U: U-shaped CFRP wraps as end anchorages; E: CFRP sheet bonded in the full span with epoxy; P: part of the CFRP sheet bonded in the beam span with epoxy resin; S: CFRP sheets were bonded onto the beam side faces. 


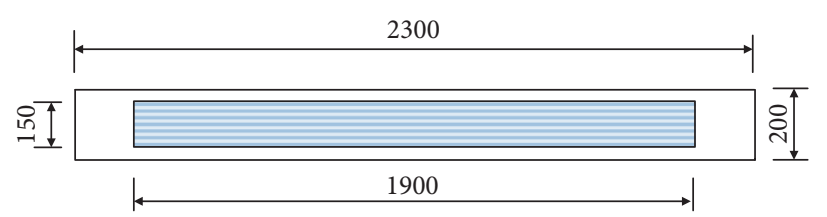

(a)

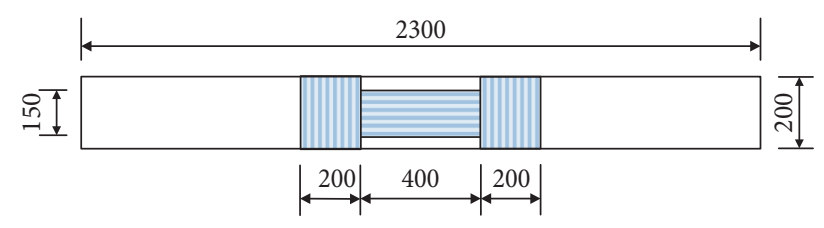

(b)

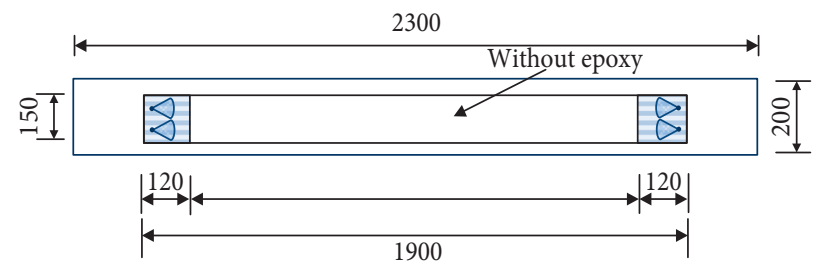

(c)

Figure 3: Layout of the CFRP sheet on Group one beams: (a) beam WE; (b) beam LEU; (c) beam WA (dimensions in mm).

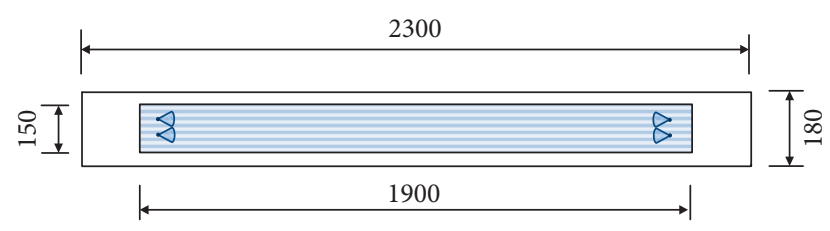

(a)

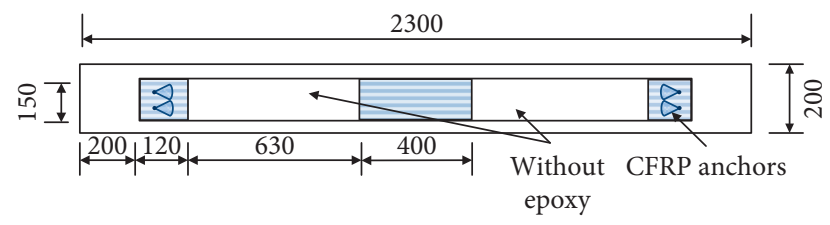

(c)

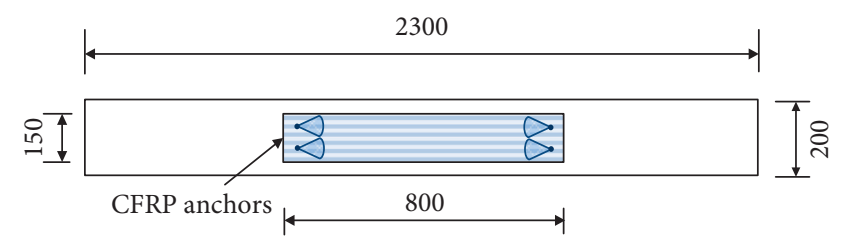

(b)

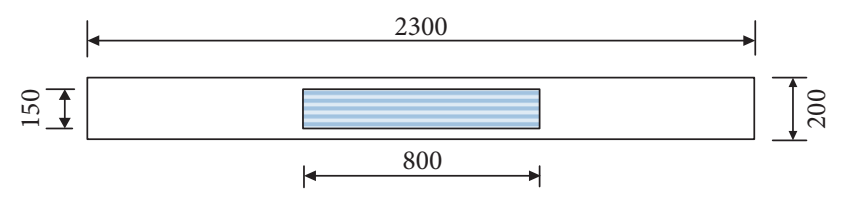

(d)

FIGURE 4: Layout of the CFRP sheet on Group two beams: (a) beam WEA-S; (b) beam LEA-S; (c) beam WPA-S; (d) beam LE-S (dimensions in $\mathrm{mm})$.

TABLE 2: Mechanical properties of carbon fibers.

\begin{tabular}{lc}
\hline Property & Value \\
\hline Fiber density & $1.8 \mathrm{~g} / \mathrm{cm}^{3}$ \\
Ply thickness & $0.381 \mathrm{~mm}$ \\
Ply weight & $230 \mathrm{~g} / \mathrm{m}^{2}$ \\
Elongation & $1.5 \%$ \\
Tensile strength & $3.45 \mathrm{GPa}$ \\
Tensile modulus & $230 \mathrm{GPa}$ \\
\hline
\end{tabular}

TABLE 3: Mechanical properties of the epoxy gel adhesive.

\begin{tabular}{lc}
\hline Property & Value \\
\hline Modulus of elasticity & $1980 \mathrm{MPa}$ \\
Tensile strength & $37.6 \mathrm{MPa}$ \\
Compressive strength & $80.5 \mathrm{MPa}$ \\
Elongation & $1.8 \%$ \\
Bending strength & $60 \mathrm{MPa}$ \\
\hline
\end{tabular}

point propagated, bond resistance was gradually lost in the zone nearest to the load but simultaneously activated a new bond zone further away from the load. This action was repeated until delamination propagated completely through the whole length of the CFRP. The length of CFRP that included the active bonded area was termed the "effective bond length." A bond model of the effective bond length $L_{\mathrm{e}}$ (m) was given by Chen and Teng [25]:

$$
L_{\mathrm{e}}=\sqrt{\frac{n E_{\mathrm{p}} t_{\mathrm{p}}}{\sqrt{f_{\mathrm{c}}^{\prime}}}},
$$

where $E_{\mathrm{p}}$ and $t_{\mathrm{p}}$ are the elastic modulus (MPa) and thickness $(\mathrm{mm})$ of the bonded plate, respectively, and $f_{\mathrm{c}}^{\prime}$ and $n$ are the cylinder compressive strength of the concrete block $(\mathrm{MPa})$ and the number of CFRP reinforcements, respectively.

The load capacity that a CFRP strip carries can increase when the bond length is less than the effective bond length. When the bonded length exceeds the effective bond length, the load capacity is not dependent on the actual bonded length. Therefore, the bonding length of aged and seriously damaged beams must be greater than the effective bond length. For beam WA, whose bond length was shorter than the effective bond length, its yield load growth was obviously much lower than that of other beams. 


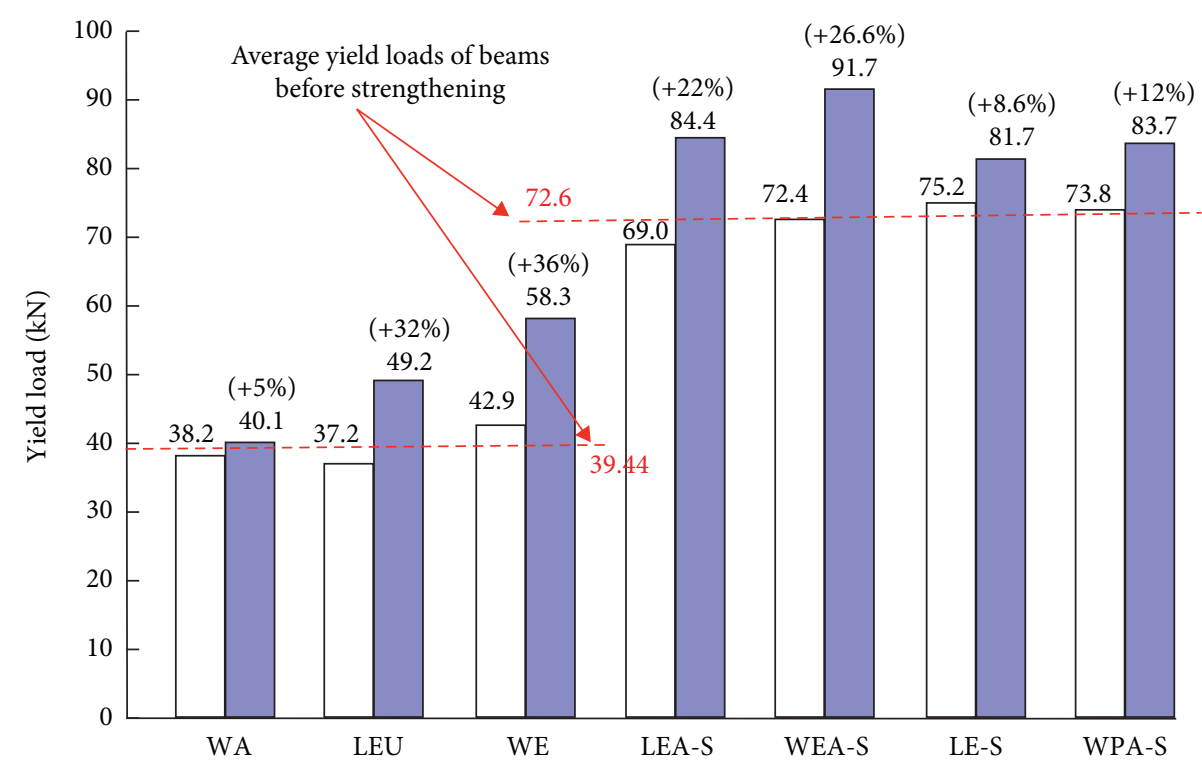

Figure 5: Increases in yield load of nonstrengthened beams and beams strengthened using CFRP.

3.1.3. Contribution of Anchoring Schemes. As illustrated in Figure 6 [26], the shear stress and normal stress were high at the ends of the CFRP laminate and decreased rapidly towards the midspan. Therefore, the separation between the CFRP laminate and the concrete face was very easy at beam ends because of stress concentrations.

Two types of anchoring schemes were used to minimize this kind of debonding tendency: $U$ wraps (U-shaped CFRP wraps) and CF anchors (carbon fiber anchors). U wraps are a type of traditional anchorage scheme that has been studied by many scholars $[27,28]$. CF anchors originally developed by the Shimizu Corporation in Japan offered a new way to anchor FRP sheets [29].

CF anchors were cut from the same CFRP sheet material that was bonded onto the beam span. Then, the CF anchors were saturated with epoxy and installed immediately into the holes. The CF anchor depth was $110 \mathrm{~mm}$. The ends of the CF anchors were fanned out over the CFRP sheet. The details of $\mathrm{CF}$ anchors and $\mathrm{U}$ wraps are shown in Figure 7.

As shown in Figure 5, beams LEA-S (CF anchors) and LEU (U-shaped CFRP wraps) both exhibited higher yield load growth compared with beam LES (not anchored) as other conditions were the same. This indicated that $\mathrm{CF}$ anchors and U-shaped CFRP wraps were both effective methods for mounting CFRP sheets to improve beam strength.

3.2. Load-Midspan Deflection Response. In Group one, the failure deflections of beams WE, LEU, and WA were $33 \mathrm{~mm}, 48.9 \mathrm{~mm}$, and $70.1 \mathrm{~mm}$, respectively (Figure 8). The deflections of beams WA and LEU were higher than those of the unanchored beam WE. During the postyielding stage, the load-deflection curves of beams LEU and WA changed the slope and then remained linear until the beams failed. In contrast, there were several sudden decreases in the postyielding stage curve of beam WE because of the sequential rupturing of the CFRP sheet.

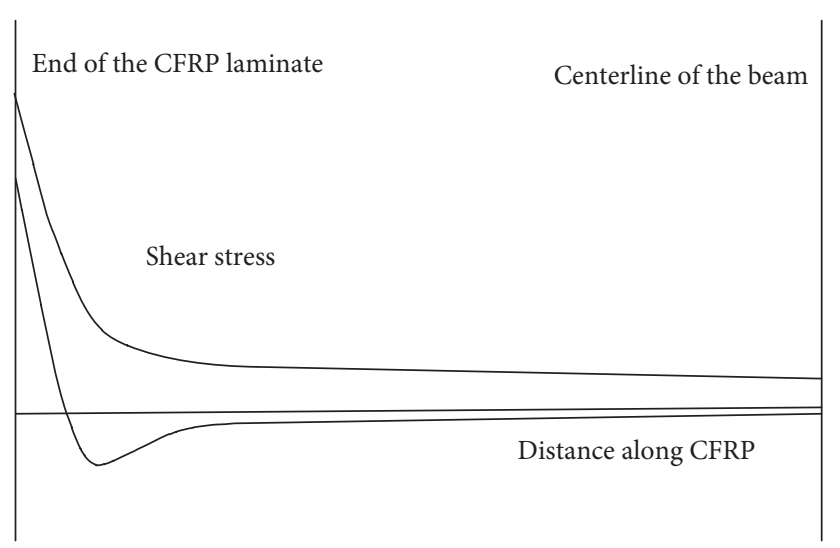

FIGURE 6: Stress variation with distance from the CFRP sheet end.

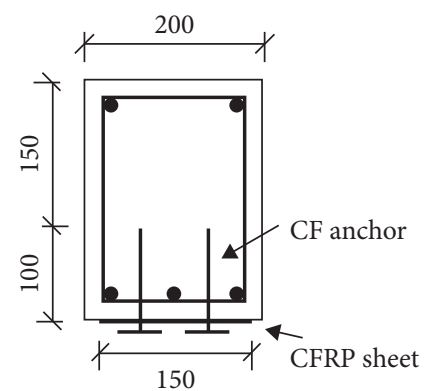

(a)

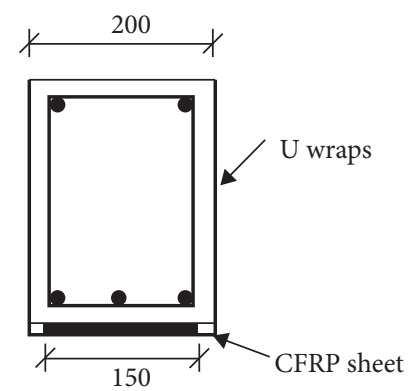

(b)
Figure 7: Detailed schemes of CF anchors (a) and U wraps (b) (dimensions in $\mathrm{mm}$ ).

In Group two, the failure deflections of beams LEA-S, WEA-S, WPA-S, and LE-S were $26 \mathrm{~mm}, 51 \mathrm{~mm}, 71 \mathrm{~mm}$, and $30 \mathrm{~mm}$, respectively (Figure 9). Due to the CF anchors, the beam WEA-S did not have sudden decreases in the loaddeflection curve compared with beam WE. The deflection of 


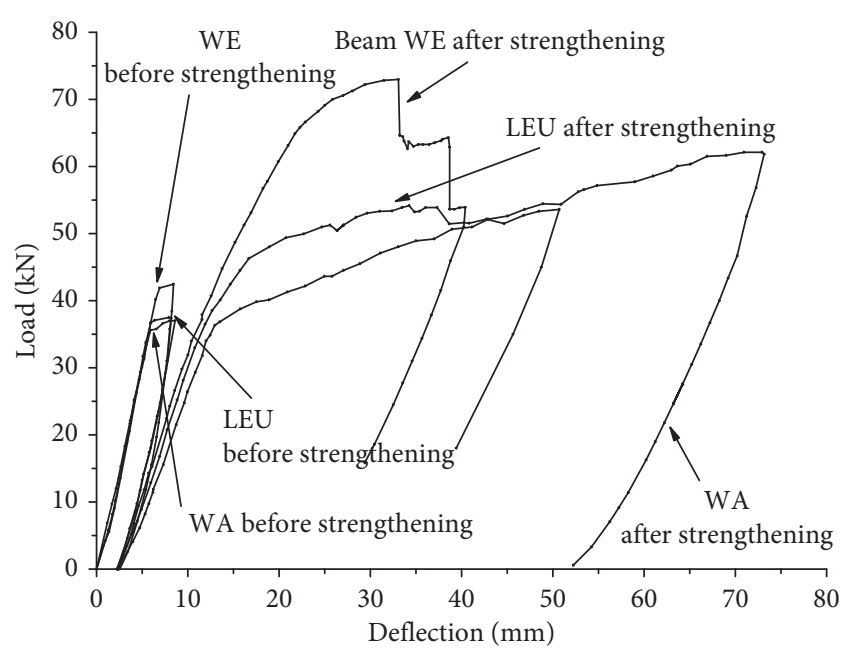

Figure 8: Load-deflection curves of Group one beams.

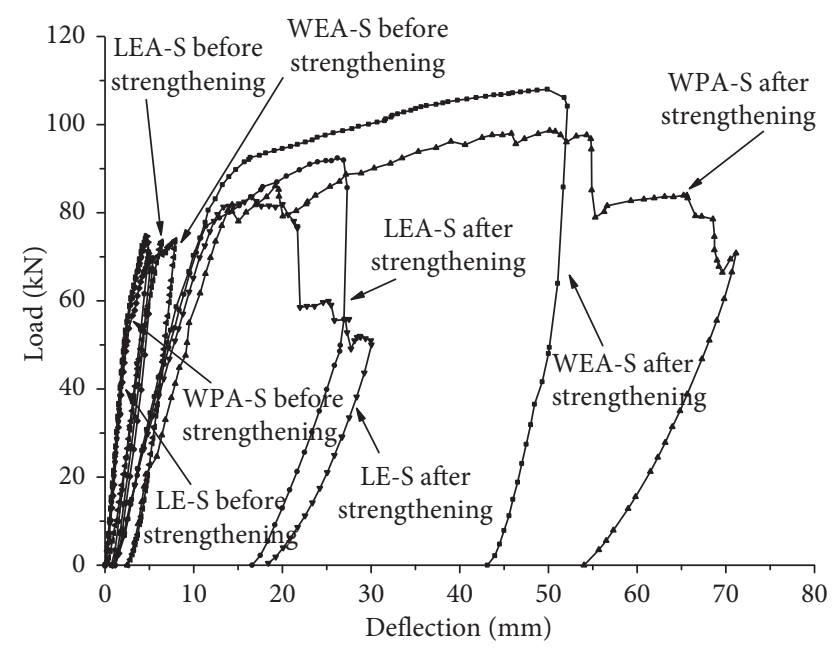

FIGURE 9: Load-deflection curves of Group two beams.

beam LEA-S was slightly smaller, but the postyield stiffness was greater than that of beam LE-S, which indicated that CF anchors could also effectively increase beam stiffness after yield load.

Beam WPA-S was strengthened in full span, but its CFRP sheet in the shear span was not bonded to the concrete face and therefore could not fully increase shear strength, in contrast to beam WEA-S. So, the yield load growth of WPAS was 15\% smaller, while the failure deflection was 34\% larger, than that of WEA-S. And the CFRP sheet in the middle flexural span of beam WPA-S would debond with the increase of load, which also caused a sudden decrease in the load-deflection curve.

During the postyielding stage, the load-deflection curve of beam LEU (U-shaped CFRP wraps) was smoother than that of beam LEA-S (CF anchors). This indicated that the strength of both increased slightly during the yield stage, but the stiffness of beam LEA-S degenerated slowly compared with beam LEU. CF anchors and U-shaped CFRP wraps could both prevent premature end-peeling of the CFRP sheet, while CF anchors could improve beam stiffness more effectively than $U$ wraps, especially in the postyield stage.

3.3. Beam Ductility. Structural ductility can be defined as a material's ability to sustain applied loads beyond the elastic limit without significant loss of load-carrying capacity until failure. Strengthening schemes using externally bonded CFRP are an important technique to influence structural ductility. Ductility can be evaluated based on a deformation ratio (or index) employing the ultimate and failure deflections. The ductility index at ultimate load $\mu_{\text {ult }}$ and failure $\mu_{\text {fail }}$ can be computed as follows:

$$
\begin{aligned}
& \mu_{\mathrm{ult}}=\frac{\delta_{\mathrm{ult}}}{\delta_{\text {yield }}}, \\
& \mu_{\text {fail }}=\frac{\delta_{\text {fail }}}{\delta_{\text {yield }}},
\end{aligned}
$$

where $\delta_{\text {ult }}=$ the beam's midspan deflection at ultimate load $(\mathrm{mm}), \delta_{\text {yield }}=$ the beam's midspan deflection at yield load $(\mathrm{mm})$, and $\delta_{\text {fail }}=$ the beam's midspan deflection at failure. The calculated ductility indices of the beams are shown in Table 4.

The ductility index decreased after beams were strengthened with the CFRP sheet. These responses indicated that the increase of load capacity would cause a reduction of beam ductility. In Group two, the yield load growth of beam LEA-S (strengthened with CF anchors) was higher than that of beam LE-S (without CF anchors). Table 4 also shows that the ductility index at failure $\mu_{\text {fail }}$ of beam LEA-S was lower, while the ductility index at ultimate load $\mu_{\text {ult }}$ was higher than that of beam LE-S. This observation indicated that beams strengthened with CF anchors would increase ductility before ultimate load.

3.4. Failure Mode. Beams strengthened with CFRP failed in a variety of modes of flexural cracks, shear cracks alone, shear cracks and debonding, flexural cracks and debonding, and bar bond splitting, as shown in Table 4 and Figure 10 .

Beam WEA-S was initiated by vertical cracks in the middle flexural span and failed by concrete crushing at the top compression zone of the midspan (Figure 10(a)). In beams WPA-S and LE-S which were not strengthened in shear spans, the shear cracks initiated first and failed due to CFRP debonding in the middle span (Figure 10(b)). The shear cracks first initiated in the shear span of beam LEU that was "U"-wrapped; then, these cracks propagated with an inclination passing through the CFRP sheets, but without CFRP debonding (Figure 10(c)).

Beam LEA-S (strengthened by CF anchors) failed in the bar bond splitting failure mode (Figure 10(d)). The bar bond splitting failure occurred suddenly by the slip between reinforcing bar and concrete interface, and the beam had a smaller deflection compared with other beams when failed. As the beam failed, the sliding between reinforcing bar and 
TABLE 4: The test results of beam specimens.

\begin{tabular}{ccccccccc}
\hline Group & Beams & $\begin{array}{c}\text { Yield load } \\
\text { growth }(\%)\end{array}$ & $\begin{array}{c}\text { Yield } \\
\text { deflection }(\mathrm{mm})\end{array}$ & $\begin{array}{c}\text { Ultimate load } \\
\text { deflection }(\mathrm{mm})\end{array}$ & $\begin{array}{c}\text { Failure } \\
\text { deflection }(\mathrm{mm})\end{array}$ & $\mu_{\text {ult }}$ & $\mu_{\text {fail }}$ & Failure mode \\
\hline \multirow{4}{*}{ One } & WE & 36 & 16.6 & 75.8 & 33 & 1.93 & 2.41 & Flexural cracks and debonding \\
& LEU & 32 & 13.5 & 55.6 & 48.9 & 2.74 & 3.62 & Shear cracks \\
& WA & 5 & 10.2 & 62.4 & 70.1 & 6.87 & 6.87 & Flexural cracks \\
\hline \multirow{6}{*}{ Two } & LEA-S & 22 & 12.6 & 91.7 & 26 & 2.02 & 2.06 & Bar bond splitting \\
& WEA-S & 26.6 & 12.5 & 109.2 & 51 & 3.91 & 4.08 & Flexural cracks \\
& WPA-S & 12 & 13.7 & 98.9 & 71 & 4.01 & 5.18 & Shear cracks and debonding \\
& LE-S & 8.6 & 13.2 & 91.7 & 30 & 1.52 & 2.40 & Shear cracks and debonding \\
\hline
\end{tabular}

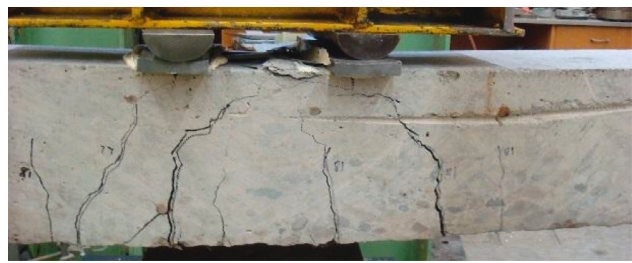

(a)

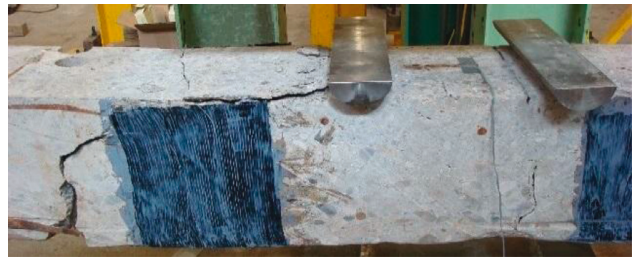

(c)

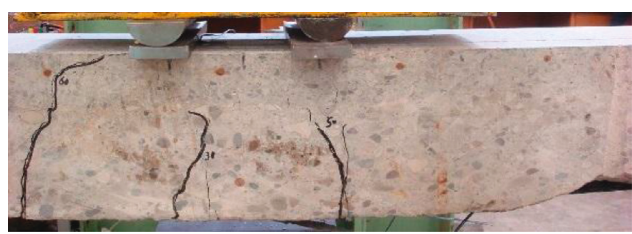

(e)

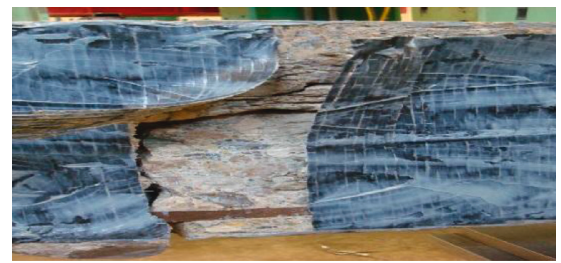

(b)

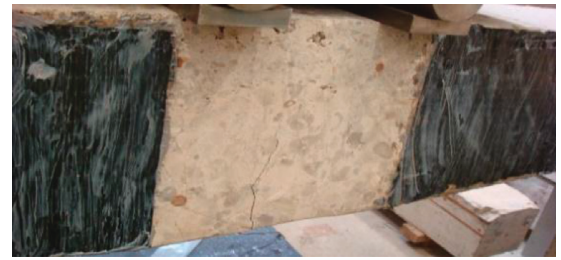

(d)

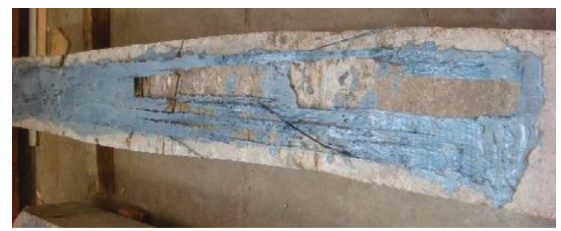

(f)

Figure 10: Failure modes of beams: (a) flexural cracks; (b) shear cracks and debonding; (c) shear cracks; (d) bar bond splitting; (e) flexural cracks and debonding (side face); (f) flexural cracks and debonding (bottom face).

concrete interface could be clearly heard. The number of cracks was also much smaller than that of other failure modes.

Beam WE was strengthened along the full span and not anchored. Its failure began with flexural cracks, followed by CFRP debonding in the middle span and failure by crushing of concrete at the top compression zone (Figure 10(e)). WA failed due to flexural cracks (Figure 10(a)) because the length of CFRP used was shorter than the effective bond length; thus, the CFRP sheet could not effectively improve the beam's load capacity.

\section{Conclusions}

This study investigated the mechanical properties of aged and seriously damaged RC beams strengthened with different CFRP sheet schemes. The experimental data justify the following conclusions.

Externally bonded CFRP sheet is an effective way to improve the flexural behavior of aged and seriously damaged
RC beams. In this study, yield load growth ranges from $5 \%$ to $36 \%$ after beams were strengthened. The yield load growth is affected by CFRP sheet dimension and position, bond length, and anchoring schemes. The beams strengthened will show higher load capacity, but in the same time will decrease the stiffness of beams.

As strengthening aged and seriously damaged RC beams, CFRP sheets should extend over the shear span to prevent or restrain the formation of shear cracks. Beam side faces also need to be strengthened with the CFRP sheet to prevent propagation of cracks.

The arrangements of external CFRP laminates and end anchorages have a significant effect on beam flexural behavior. In order to have a good strengthening effect, the CFRP bond length must be longer than the effective bond length. Stress concentrates at the CFRP laminate end and decreases rapidly in the midspan direction. $\mathrm{U}$ wraps and $\mathrm{CF}$ anchors can effectively prevent premature end-peeling of the CFRP sheet, and CF anchors improve beam stiffness more 
effectively compared with $U$ wraps, especially in the postyield stage. Beams strengthened with CF anchors can increase ductility in the yielding stage compared to beams with no anchors.

Aged and seriously damaged RC beams strengthened with the CFRP sheet fail in a variety of modes including flexural cracks, shear cracks, shear cracks and debonding, flexural cracks and debonding, and bar bond splitting. The results from this study, and the conclusions they support, can be applied in engineering and construction practice to guide the repair of aged and seriously damaged RC beams.

\section{Notations}

$\alpha_{\text {yield }}$ : The percent increase of the yield load

$f_{\text {str }}$ : The yield load after strengthening (MPa)

$f_{\text {bef }}$ : The yield load before strengthening $(\mathrm{MPa})$

$L_{\mathrm{e}}$ : The effective bond length $(\mathrm{m})$

$E_{\mathrm{p}}$ : The elastic modulus ( $\left.\mathrm{MPa}\right)$ of the bonded plate

$t_{\mathrm{p}}$ : The thickness $(\mathrm{mm})$ of the bonded plate

$f^{\prime}$ : The cylinder compressive strength of the concrete block (MPa)

$n$ : $\quad$ The number of CFRP reinforcements

$\delta_{\text {ult }}$ : The beam's midspan deflection at ultimate load ( $\left.\mathrm{mm}\right)$

$\delta_{\text {yield }}$ : The beam's midspan deflection at yield load $(\mathrm{mm})$

$\delta_{\text {fail }}$ : The beam's midspan deflection at failure

$\mu_{\text {ult }}$ : The ductility index at ultimate load and failure

$\mu_{\text {fail }}$ : The ductility index at failure.

\section{Data Availability}

The data used to support the findings of this study are included within the article.

\section{Conflicts of Interest}

The authors declare that they have no conflicts of interest.

\section{Acknowledgments}

This work was supported by the National Natural Science Foundation of China (51679080 and 51379073), Fundamental Research Funds for the Central Universities (2018B655X14), Postgraduate Research and Practice Innovation Program of Jiangsu Province (KYCX18_0630), and Scientific and Technology Project of Jiangsu Provincial Water Resources Department (2017030) and sponsored by Qing Lan Project.

\section{References}

[1] V. Alecci, S. B. Bati, and G. Ranocchiai, "Concrete columns confined with CFRP wraps," Materials and Structures, vol. 47, no. 3, pp. 397-410, 2014.

[2] N. Attari, S. Amziane, and M. Chemrouk, "Flexural strengthening of concrete beams using CFRP, GFRP and hybrid FRP sheets," Construction and Building Materials, vol. 37, no. 3, pp. 746-757, 2012.

[3] C. Jiang, K. Fan, F. Wu, and D. Chen, "Experimental study on the mechanical properties and microstructure of chopped basalt fibre reinforced concrete," Materials and Design, vol. 58, pp. 187-193, 2014.

[4] R. Eid, N. Roy, and P. Paultre, "Normal and high-strength concrete circular elements wrapped with FRP composites," Journal of Composites for Construction, vol. 13, no. 2, pp. 113-124, 2009.

[5] H. K. Shehab, A. S. Eisa, and K. A. El-Awady, "Strengthening of cutouts in existing one-way Spanning R. C. Flat slabs using CFRP sheets," International Journal of Concrete Structures and Materials, vol. 11, no. 2, pp. 327-341, 2017.

[6] N. Zhuang, Y. Zhou, and H. Sun, "Effects of steel reinforcement corrosion on carbon-fibre-reinforced polymer repaired slabs," Proceedings of the Institution of Civil Engineers-structures and Buildings, vol. 169, no. 1, pp. 46-53, 2015.

[7] B. B. Adhikary and H. Mutsuyoshi, "Behavior of concrete beams strengthened in shear with carbon-fiber sheets," Journal of Composites for Construction, vol. 8, no. 3, pp. 258-264, 2004.

[8] I. A. Bukhari, R. Vollum, S. Ahmad, and J. Sagaseta, "Shear strengthening of short span reinforced concrete beams with CFRP sheets," Arabian Journal for Science and Engineering, vol. 38, no. 3, pp. 523-536, 2013.

[9] T. Norris and H. Saadatmanesh, "Shear and flexural strengthening of R/C beams with carbon fiber sheets," Journal of Structural Engineering, vol. 123, no. 7, pp. 903-911, 1997.

[10] M. J. Chajes, T. F. Januszka, D. R. Mertz, T. A. T. Jr, and W. W. F. Jr, "Shear strengthening of reinforced concrete beams using externally applied composite fabrics," ACI Structural Journal, vol. 92, no. 3, pp. 295-303, 1995.

[11] P. V. Llauradó, J. Fernández-Gómez, and F. J. G. Ramos, "Influence of geometrical and installation parameters on performance of CFRP anchors," Composite Structures, vol. 176, pp. 105-116, 2017.

[12] S. V. Grelle and L. H. Sneed, "Review of anchorage systems for externally bonded FRP laminates," International Journal of Concrete Structures and Materials, vol. 7, no. 1, pp. 17-33, 2013.

[13] F. M. Mohee, A. Al-Mayah, and A. Plumtree, "Development of a novel prestressing anchor for CFRP plates: experimental investigations," Composite Structures, vol. 176, pp. 20-32, 2017.

[14] J. G. Teng, L. Lam, W. Chan, and J. Wang, "Retrofitting of deficient RC cantilever slabs using GFRP strips," Journal of Composites for Construction, vol. 4, no. 2, pp. 75-84, 2000.

[15] C. P. Pantelides and G. Fitzsimmons, "Case study of strategies for seismic rehabilitation of reinforced concrete multicolumn bridge bents," Journal of Bridge Engineering, vol. 17, no. 1, pp. 139-150, 2012.

[16] G. Zanardo, H. Hao, Y. Xia, and A. J. Deeks, "Evaluation of the effectiveness of strengthening intervention by CFRP on MRWA bridge no. 3014," Journal of Composites for Construction, vol. 11, no. 4, pp. 363-374, 2007.

[17] G. Williams and C. Higgins, "Fatigue of diagonally cracked RC girders repaired with CFRP," Journal of Bridge Engineering, vol. 13, no. 1, pp. 24-33, 2008.

[18] I. Ray, G. C. Parish, J. F. Davalos, and A. Chen, "Effect of concrete substrate repair methods for beams aged by accelerated corrosion and strengthened with CFRP," Journal of Aerospace Engineering, vol. 24, no. 2, pp. 227-239, 2010.

[19] D. Zhang, S. Shen, Y. Zhao, W. Jin, and T. Ueda, "Cracking behavior of CFRP laminate-strengthened RC beams with premechanical and postmechanical environmental damage," Journal of composites for construction, vol. 19, no. 4, article 04014066, 2014.

[20] S. J. E. Dias and J. A. O. Barros, "NSM shear strengthening technique with CFRP laminates applied in high-strength 
concrete beams with or without pre-cracking," Composites Part B: Engineering, vol. 43, no. 2, pp. 290-301, 2012.

[21] S. B. Zhao, J. F. Li, F. J. Shi, and Z. H. Du, "Shear resistance of pre-cracking reinforced concrete T-beam strengthening with CFRP sheets," Applied Mechanics and Materials, vol. 438-439, pp. 472-476, 2013.

[22] ASTM, G1-90: Standard Profile for Preparing, Cleaning, And Evaluating Corrosion Test Specimens, ASTM International, West Conshohocken, PA, USA, 1999.

[23] K. Joongkoo, "A study on structural performance evaluation of RC beams strengthened with CFRP plate," Korean Journal of Construction Engineering and Management, vol. 5, no. 6, pp. 212-217, 2004.

[24] C. Zeris, J. Anastasakis, and J. Kyriakidis, "Investigation of monotonic and cyclic response of fiber-reinforced polymer strengthened beams," ACI Structural Journal, vol. 106, no. 1, pp. 3-13, 2009.

[25] J. F. Chen and J. G. Teng, "Anchorage strength models for FRP and steel plates bonded to concrete," Journal of Structural Engineering, vol. 127, no. 7, pp. 784-791, 2001.

[26] M. T. El-Mihilmy and J. W. Tedesco, "Prediction of anchorage failure for reinforced concrete beams strengthened with fiberreinforced polymer plate," ACI Structural Journal, vol. 98, no. 3, pp. 301-314, 2001.

[27] A. U. R. Khan and S. Fareed, "Behaviour of reinforced concrete beams strengthened by CFRP wraps with and without end anchorages," Procedia Engineering, vol. 77, pp. 123-130, 2014.

[28] W. Li and C. K. Y. Leung, "Effect of shear span-depth ratio on mechanical performance of RC beams strengthened in shear with U-wrapping FRP strips," Composite Structures, vol. 177, no. 1, pp. 141-157, 2017.

[29] M. Kaya and Z. Ç. Kankal, "Effect of anchorage number on behavior of reinforced concrete beams strengthened with glass fiber plates," International Journal of Concrete Structures and Materials, vol. 9, no. 4, pp. 415-425, 2015. 


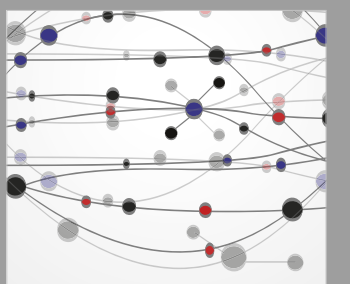

The Scientific World Journal
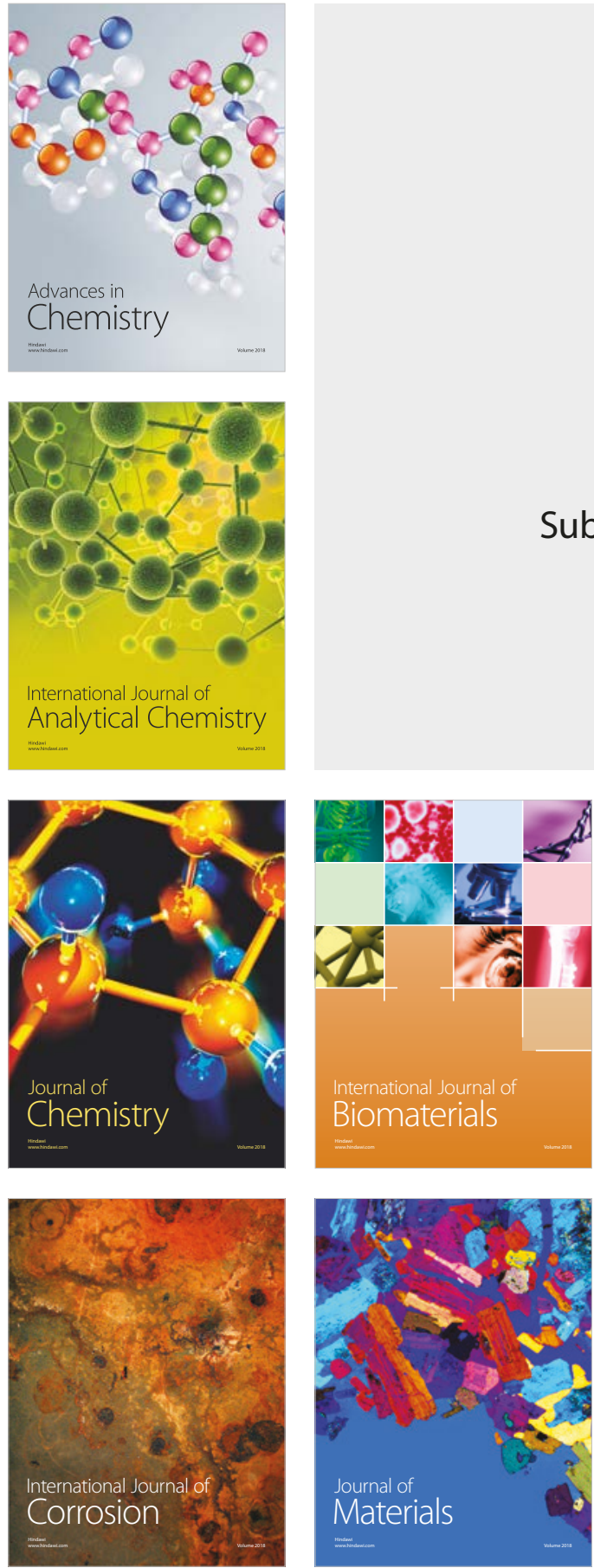

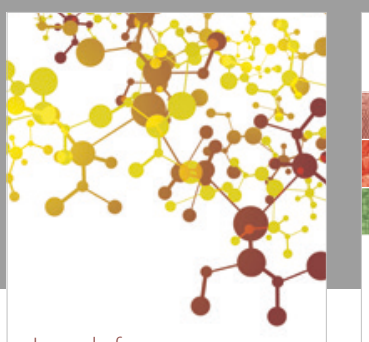

Journal of

Applied Chemistry
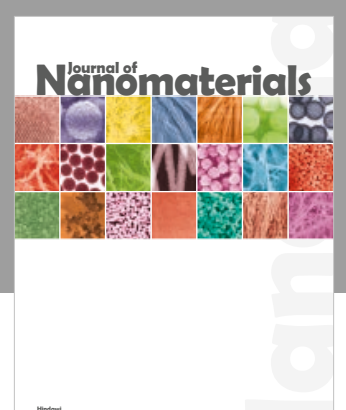

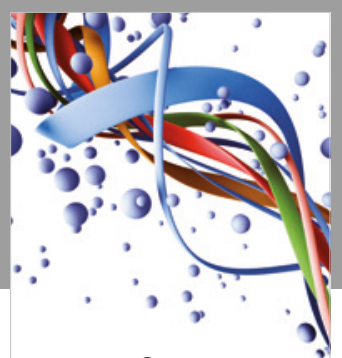

Scientifica

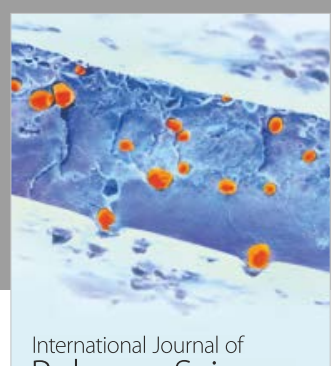

Polymer Science

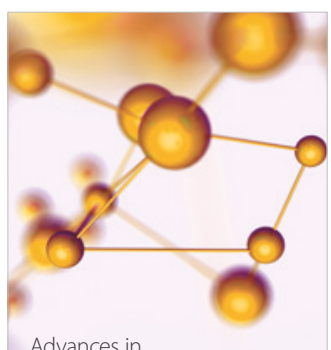

Physical Chemistry
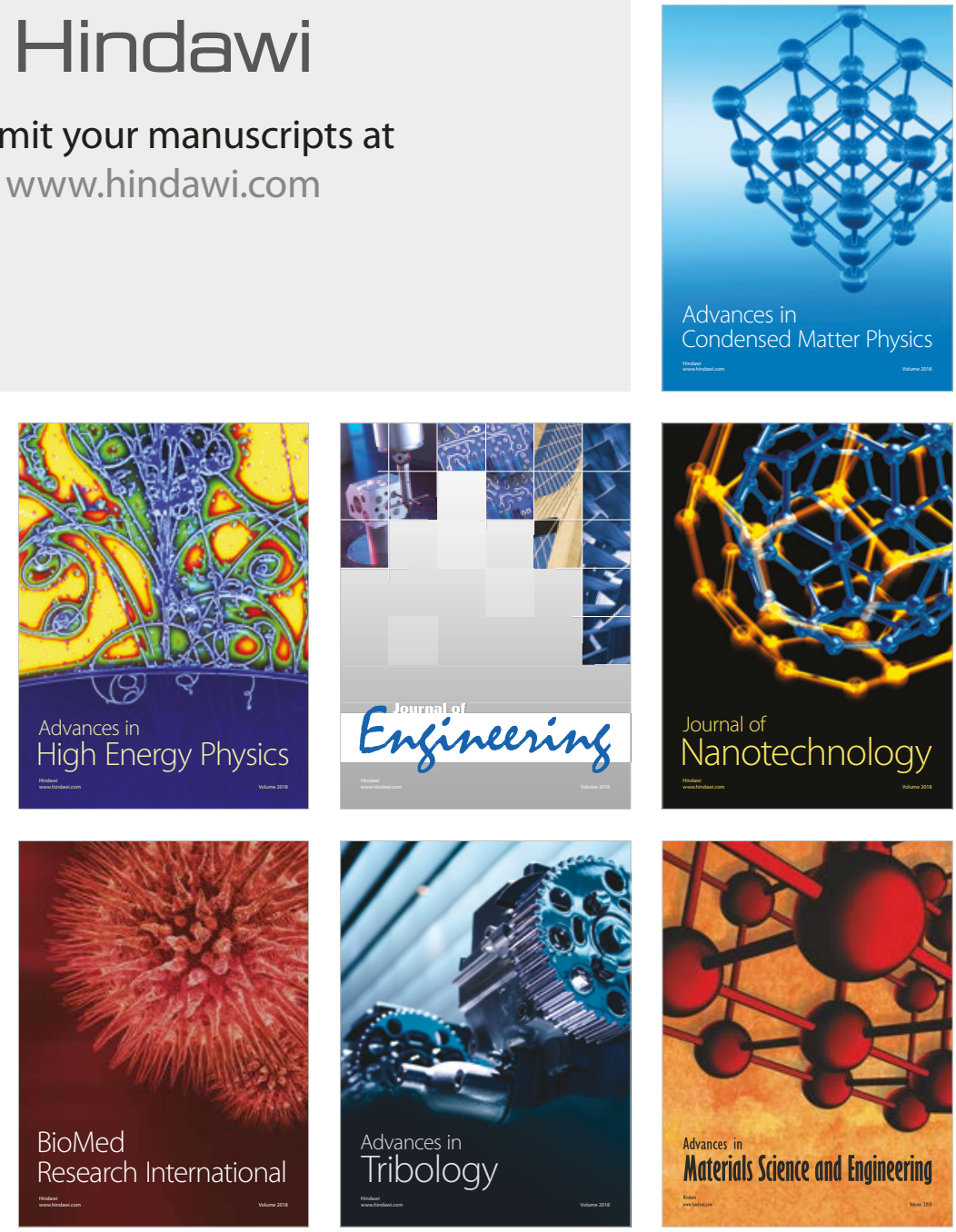